\title{
Engaging Narratives and the Limits of Lay Ethics: Introduction
}

\author{
Alfred Nordmann • Phil Macnaghten
}

Received: 26 July 2010 / Accepted: 26 July 2010 / Published online: 12 August 2010

(C) Springer Science+Business Media B.V. 2010

\begin{abstract}
How can one discover the ethical issues associated with nanotechnologies? One heuristic is to tend closely to the ethical reflections of lay publics and the ways in which these are informed by experience with technological innovation, technology governance, and the (broken) promises of visionary science and technology. A close collaboration between social scientists and philosophers took this heuristic to its limits: On the one hand, it achieved remarkably finegrained insights into public reflection about nanotechnologies. On the other hand, a philosophical analysis of these reflections makes apparent that there is a profound disconnect between the lay ethics rooted in public talk and the ethical and normative commitments that are embedded in nanotechnological research programs and practices. Accordingly, critical engagement with the ways in which ordinary people try to make sense of nanotechnologies constitutes a novel heuristic for the discovery of ethical issues. This introduction and the subsequent four papers show this heuristic at work.
\end{abstract}

\footnotetext{
A. Nordmann $(\bowtie)$

Philosophy Department, Darmstadt Technical University, Darmstadt, Germany

e-mail: nordmann@phil.tu-darmstadt.de

P. Macnaghten

Geography Department, Durham University,

Durham, UK

e-mail: p.m.macnaghten@durham.ac.uk
}

Keywords Heuristics for the discovery of ethical issues - Narratives - Conversation and deliberation . Language games of ethics

The European Commission issued in 2005 a call for proposals for projects that aimed at "deepening understanding of ethical issues."1 One of the projects funded under this call, the so-called DEEPEN project, offered cross-disciplinary research that aimed towards the identification and characterization of the ethical issues posed by emerging nanotechnologies. This understanding was to develop from the sustained interplay of a normative perspective provided by philosophical analysis and the deliberative engagement with publics, stakeholders and the nanoscience community. Among the various findings of this project, one is of particular interest for nanoethics: while the DEEPEN project began with one understanding of what it might mean to deepen ethical understanding, it ended with quite another. But where one of its aspirations was disappointed, new insights

\footnotetext{
${ }^{1}$ See call 4.3.2.3 "Deepening the understanding of ethical issues" of the European Commission's Science and Society Work Programme 2006. The stated objective was "research on ethics" in the fields of nanotechnological developments, including "comparative research, foresight, and impact studies" of the "legal, social, economic, and cultural impact" of these fields. However, one of the funded projects under this call sought mainly to promote deepened understanding by relevant social actors such as trade unions and environmental NGOs, see www.nanocap.eu (accessed July 5, 2010) and for a synoptic presentation van Broekhuizen and Schwarz [19].
} 
became possible. This multi-disciplinary learningprocess will be reconstructed in this special issue. The four papers represent a sequence of stages in the interplay between on the one hand empirically grounded social science research on the values and considerations that surface when people reflect on nanotechnology in real-world circumstances, and on the other hand systematic considerations of nanotechnology within a normative conception of ethics. The papers jointly highlight the new thinking on 'nanoethics' which emerged over the course of the project. ${ }^{2}$

\section{Circumspect Aspirations}

The DEEPEN project brought together philosophers from Germany, France, and the Netherlands with social scientists from the United Kingdom, Portugal, and the Netherlands. ${ }^{3}$ What brought these diverse partners together was a vague dissatisfaction with the process institutionally cast as the "responsible development of nanoscience and nanotechnologies" and, in particular, with the framing of the debate and the roles assigned to social scientists and philosophers in the process. In particular, we criticized the notion: (1) that the motivation to engage stakeholders and lay publics should be primarily that of creating a climate of trust and acceptance; (2) that the interests of publics should be reduced to questions of risks and benefits; and (3) that public engagement methodologies should be seen as a more or less sophisticated form of opinion research. We also rejected the speculative character of much extant nanoethics. According to speculative ethics, issues are discovered by taking seriously visionary announcements that particular disruptive technological capabilities will exist within a more or

\footnotetext{
${ }^{2}$ The main contributors to the DEEPEN-project were Phil Macnaghten, Sarah Davies, and Matthew Kearnes (Durham), Arie Rip and Clare Shelley-Egan (Twente), João Nunes, Marisa Matias, Ângela Marques Filipe, and Antonio Carvalho (Coimbra), Alfred Nordmann and Arianna Ferrari (Darmstadt). Jean-Pierre Dupuy served as a discussant and commentator on the project. This introduction offers a philosophical reconstruction of DEEPEN's contribution to nanoethics. Like all reconstructions, it offers a narrative with the benefit of hindsight. Quite another narrative could be constructed in respect to questions of governance or in respect to public engagement methodologies. See Macnaghten, Davies and Kearnes [13], and Rip and Shelley-Egan [18].

${ }^{3}$ For more detail see www.geography.dur.ac.uk/projects/deepen/, accessed July 5, 2010
}

less remote- and by current standards incrediblefuture $[14,15]$. However, the DEEPEN collaborators were also not satisfied with the idea that, for the understanding of ethical issues, no process of discovery is required at all and that rote issues of surveillance and privacy, bodily harm, equality of access, rights to know or not to know simply reappear in nanotechnological guise. We distrusted, in other words, the notion that there is a given and a priori set of recognizable ethical issues and that one should simply look out for those nanotechnological developments that trigger such ethical sensibilities.

From this dissatisfaction the DEEPEN plan of action was born. It consisted of two ways of stepping back from contemporary notions of "responsible development" and starting afresh. On the one hand, the very idea that there are preconceived notions of what ethics is and does, and what ethical issues look like, prompted a social science analysis of how this conception of ethics informs a division of moral labor between laboratory researchers and social science or humanities scholars. Interviews with industrial and scientific enactors of nanotechnology research did not set out to probe only whether they considered ethical questions important or what they thought some of the ethical issues were. Instead, the questions sought to elicit ideas about the significance of ethical deliberation for their own work, and about the ways in which nanoethical discourse should enter the process of responsible development. It turned out to be more than a story of unambiguous technological progress that can only be threatened or delayed by undue attention to ethical and societal aspects. Taking responsibility and creating trust were explicit concerns, but there was also reference to existing divisions of moral labor which could and should be continued-even as the notion is challenged on various fronts that scientists do science, while advisory committees and society at large deal with any ethical or social implications [18].

On the other hand, DEEPEN also initiated a process of discovery of ethical issues that brought together social science methodology and philosophy. Here, the plan of action looked like this: after engaging selected groups of citizens in the UK and Portugal, a close reading of their communal reflections about nanotechnology would reveal themes which could be taken up by ethicists and social theorists. Rather than involving rote considerations of-for 
example - privacy or bodily harm, the emergent issues raised in lay discussion would prove their relevance in two ways. First, to the extent that they arose directly in response to presentations about nanotechnologies in pertinent real-world contexts, they are certifiably germane without needing to be specific (in the sense of applying only to nanotechnologies and nothing else). Second, the concerns expressed by citizens were not just summarised and recorded - as they would be in opinion research-but also interpreted and taken seriously as a heuristic for ethical discussion at the European level. ${ }^{4}$ In contrast to speculative ethics, these matters of concern 'in-the-making' would reflect historical experience with past technologies and their governance. This methodology led to the richly textured findings presented in the paper "Narratives of mastery and resistance: Lay ethics of nanotechnology" by Sarah Davies and Phil Macnaghten (see below).

It was here, however, that a discrepancy surfaced between the original aspiration and what was finally achieved regarding a deepened understanding of ethical issues. Are the values that underpin citizens' narratives of mastery and resistance so incommensurate with those of nanoscale science and engineering that they may fail as a straightforward heuristic for an ethical understanding of nanotechnologies? Are they, perhaps, symptomatic of a kind of blind gropingone which is characteristic not just of lay but also of most academic responses to nanotechnology so far, regardless of whether they proceed from speculation, by rote ethical stereotype, or from experience with technological novelty in the past?

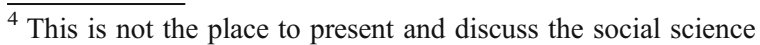
methodology in detail. Since this was not opinion research but served a heuristic function, the selected citizens did not need to be statistically representative. Nevertheless, while we did not seek representativeness (being interested more in the range and variability of meanings in the population at large), we nevertheless aimed to tap into segments of society that are situated at the fault-lines out of which public responses to nanotechnology are likely to develop. Groups were selected around commonalities of lifeworld experience such that their selection allowed a contrast between more clearly technologyfriendly and skeptical constituencies. Further controls to validate the findings included extensive opportunities for all participants in the engagement-exercises to learn about nanotechnologies from a variety of sources and perspectives. Also, the process of close reading that led to the identification of core concerns was rendered intersubjective through a process of mutual criticism.
}

\section{The Conversational Mode ${ }^{5}$}

If one wants to understand the complexity of citizens' concerns and the ways in which their deliberations can and should inform directly the discovery of relevant ethical issues, it may help to take a closer look at the language game of "responsible development of nanotechnology", as it tends to be enacted by institutionally-sponsored initiatives of public engagement (for a review of recent initiatives, see [4]). This language game proceeds in a conversational mode and is characterized by its largely enumerative and accommodating grammar of concern. ${ }^{6}$ This sets it apart from other language games that revolve around ethical problems, such as individual conflictedness or social conflict, real and imagined dilemmas, or around the exploration, in moral philosophy, of irresolvable conflicts of value and principle.

The predominance of the merely enumerative and accommodating language of concern is a worldwide phenomenon but is especially pronounced, perhaps, in Europe, where stakeholders and citizens tend to be invited to take part in an on-going conversation about nanotechnology and thereby to contribute, along with nano-researchers and policy makers, to its responsible development [16]. It is a conversation precisely in the sense that everyone can join in and say their piece: it is an open-ended, accommodating, process that incorporates opinions that vary considerably in topicality and scope. Since no participant in a conversation is thought to speak from a position of self-interest and since the conversation does not culminate in a decision that will cost some and benefit others, participants need not prevail over each other but can afford to listen as various concerns are

\footnotetext{
${ }^{5}$ Much of this section is adapted and expanded from unpublished Deliverable 11 "Analytical Input Statement: Philosophical Analysis and Formulation of Input into Deliberative Fora" of the DEEPEN project.

${ }^{6}$ Bruno Latour $[8,9]$ contrasts matters of fact and matters of concern. This is pertinent especially for the consideration of the ontologies of science and of technoscience. In the context of ethics, matters of (mere) concern need to be contrasted with problems, conflicts, dilemmas. What the technosciences produce is a matter of concern - we worry about how they change the world and therefore tend attentively to their promises and deliverances. But the vagueness of worries is a far cry from the sharpness of conflict that needs to be resolved (and, perhaps, cannot be resolved) or the seriousness of a problem that weighs heavily and slows us down.
} 
raised. $^{7}$ The mention of any concern extends the conversation, provoking further expressions of concern, and all of these remain at a safe distance from claims of imminent danger or intolerable offence. As such, conversations are carried on in a consensual manner, though consensus is not the endpoint of the conversation. A conversation can go on indefinitely, and tolerates agreements and disagreements equally well. Indeed by entering the language game of responsible development and concern, the participants in the conversation create room for considerable disagreement on the basis of the shared understanding that responsible development of nanotechnology is possible and desirable in the first place, and that one contributes to it by articulating concerns. ${ }^{8}$ The commitment to responsibility or sustainability as an unquestioned common good is weak but inclusive: it allows a company like DuPont to collaborate with Friends of the Earth, and for Greenpeace or the ETC Group to join stakeholder conferences at the European Commission. And to the extent that this conversational format brings all actors together, more conflictual situations are less likely to arise.

This understanding of the predominant language game of concern created a predicament for the avowed aspirations of the DEEPEN project. The aim that was envisioned for the project by its European funding agency was to contribute to this unending conversation. In the larger context of "responsible development of nanotechnology" it was to complement existing surveys and reports of ethical and societal aspects and to extend the catalogue of concerns regarding problems that might arise. Indeed, it is debatable that the very openness and openendedness of public engagement exercises, in the form of focus groups and other group deliberative

\footnotetext{
${ }^{7}$ To be sure, this idealized description of the language game of responsible development and ethical concern does not do justice to the subtle play of normativities and power which also occurs in conversational contexts. While it captures the way in which representatives of industry and science and policy all appear to speak as private individuals when concerns are raised and enumerated, it does not provide a full account of the complicated positionings that occur when a catalogue of relevant concerns is produced for a report, say, about ethical and societal aspects of nanotechnology.

${ }^{8}$ According to Ludwig Wittgenstein in the Philosophical Investigations (remark 241), by agreeing in the language we use we are not agreeing in opinion but in a shared form of life. The conversational language of concern affords a form of life that accommodates disagreement.
}

exercises, benefits the conversational format, affording an atmosphere of trust and of comparatively unguarded communication that tends to reproduce, unwittingly perhaps, a stable and malleable apolitical image of 'the public' - one that is also arguably conducive to governmental control and management [10]. With these points in mind, the DEEPEN research paid close attention not simply to the structure of conversation that took place among citizens, but also to the specific cultural dynamics and political economy through which new and different concerns were brought to light, alongside the repertoire of stories and cultural resources that gave rise to these concerns. Thus, while we are not attributing to the experience of "ordinary citizens" privileged position and insight, ${ }^{9}$ we would nevertheless maintain that the DEEPEN process, as set out by Sarah Davies and Phil Macnaghten below, helped articulate the shared and culturally-specific narratives that shape and structure latent public concern, and thus the reasons why particular concerns cannot be reduced simply to a list (see also [3]). These points are especially relevant for the purposes of governance that has to take account of citizens' attitudes. And thus, though the articulation of citizens' concerns contributes to the unending conversation, its critical uptake by the DEEPEN project seeks to move ethics discourse beyond the conversational mode of cataloguing concerns, and beyond the limits imposed by the dominant regime of "responsible development." And whereas the concerns raised in the conversational mode may or may not be adequate to the specific challenges and implicit values of nanotechnological research and development, the DEEPEN project explicitly probed their adequacy and thereby determined the relevant ways of taking them seriously.

A systematic framework for this approach was provided by Jean-Pierre Dupuy and Alexei Grinbaum who defend a vision of moral philosophy which is irreducible to the conversational mode [6]. They suggest that the language game of responsible development and concern is tied to a particular

\footnotetext{
${ }^{9}$ However, one should also not dismiss too quickly the idea that historical experience with the promises and delivery of new technologies does in fact afford a privileged no-nonsense attitude and insight amongst workers, consumers, and voting publics - especially if it were also the case that the promises and realities of nanotechnology are not substantially different from other highly-touted technologies.
} 
orientation towards the future, and, in particular, to a "logic of detour" that is characteristic of consequentialist approaches to ethics. Following Dupuy and Grinbaum, a heuristic for ethics does not lie in the discovery of new concerns but in conceiving the future differently; that is, in terms of "projected" rather than "occurring" time. It is only thus that the pressing issues of our times can gain traction. This contrast requires further elaboration, especially as it pertains to the difference between values and concerns expressed in conversational narratives and the philosophical as well as ethical analysis of nanotechnological research programs.

In temporal terms, the grammar of concern involves an orientation towards imagined futuresnote the plural! - that is, towards that which will or may occur in time. The humble starting point of conversationalists is that they are not actually producing the future, but preparing for what may come. They behold images of the future from the fairly safe distance of the present, they relate to these images by liking or disliking what lies ahead, by embracing certain scenarios and worrying about others. Epistemically, their relation to the future as that which will eventually occur is characterized by uncertainty. Conversations about likely and unlikely, desirable and undesirable futures are accordingly framed within a notion of occurring time and its asymmetry between the past (known and given) and the future (coming toward us, as yet undetermined, unknown). Within the language game of concern, attitudes towards possible futures are often focused through stimulus material such as the depiction of alternative scenarios. This kind of conversation fosters what Dupuy calls "a rationality of the detour" which he sees as inextricably wedded to consequentialism: in order to determine what might or ought to be done, one first assumes a hypothetical course of action and a possible future as its consequence, and only by assessing this one among indefinitely many possible futures does one assess what should be done. The accommodations within the conversational mode are therefore not only to one another (in the sense of the conversationalist constantly adapting to the concerns of others) but also to imagined futures and what they are thought to hold (in the sense of adapting to technological capacities). In effect, then, the language game of ethical concern and responsible development matches categories of concern (privacy, safety, distributional justice, owner- ship) to imagined technological developments. Speculative ethics does this, notions like preparedness, foresight, anticipatory governance aim for this, and moratoria assert the need for a mutual accommodation of what is or who we are now and what will be or may occur. $^{10}$

In contrast to all of this, the notion of projected time makes room for moral philosophy and a different kind of philosophical analysis. Its starting point is the symmetry of future and past. Just as there is only one past that causally determines the present situation, there is also only one future that influences how we act today. This future is not the one that conversationalists await but rather one that citizens and decisionmakers in the political sphere are fixed upon-either the catastrophe that is bound to come and therefore must be prevented, or a state so strongly desired that it must be produced. ${ }^{11}$ There is a crucial difference, therefore, between the conversational concern that this or that future occurrence would be catastrophic, and the conviction that we are heading towards a catastrophe. Belief that the present inevitably leads to catastrophe elevates matters of concern to matters of survival and moral struggle. Such belief also inaugurates a very different language game, one that is not indefinite and open-ended but rather seeks closure, since it is fixed upon a projected future that demands to be accepted or refused, realized or prevented. Instead of being conversational, this language game might be called deliberative in the sense of moral philosophy: it seeks to resolve towards necessary action an otherwise irresolvable conflict of principles.

It is perhaps controversial whether the present condition of nanotechnological research and development implies a catastrophic future (for Dupuy, the catastrophe resides within the flawed ambition to control the out-of-control). Similarly, it is very much

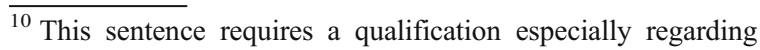
the notion of anticipatory governance. The proposed form of governance does not suppose an imagined technological future but only that there is considerable uncertainty regarding the variety of imagined futures. It therefore aims for a more general state of preparedness, one that will achieve the mutual accommodation of who we are to what might be coming.

${ }^{11}$ Dupuy took on the difficult task of developing a logic of time that allows for a future that, like the past, is positively given, but that still allows for an event to break this loop (e.g. [5]). In his contribution to this special issue, he offers as an example and success-story of projected time the logic of "mutually assured destruction."
} 
an open question whether nanotechnological research programs pursue a desirable state that we might fix upon as something that must be realized. Either way, the projected future acts upon the present not only in the sense that it requires action for its realization but also in that it challenges and undermines this present in a variety of ways. ${ }^{12}$ To fix upon this future is thus to evaluate the present: what precisely is the problem in or with the present that requires a nanotechnological solution or that would benefit from one? It is here that the rationality of the detour can be avoided and a more immediate but conflictual stance towards competing values developed-one that, in the words of Bernadette Bensaude-Vincent, involves a "requalification, an empowerment of the political sphere" [2]. And it is here that one can judge whether citizens' concerns challenge moral philosophy in a way that is adequate to the future projected by the nanotechnological program of research and development.

In his contribution, Jean-Pierre Dupuy subjects citizens' concerns to just this kind of scrutiny and finds that they are most pertinent not in their particulars but in a telling pattern. After they were presented with different scenarios of nanotechnological futures, some positive others negative, all in the public sphere, each of the groups was encouraged to deliberate on their plausibility in the light of current political economy dynamics and governance arrangements. In all of the focus groups, both in the UK and in Portugal, though not in Brazil, people arrived at tragic conclusions, believing that under real-world conditions nanotechnologies would lead to disaster of some kind (compare [12]). This general pattern among European publics resonates with Dupuy's analysis that at the heart of nanotechnological research programs lies the dangerous desire to control that which is out-of-control (see also [11]). In other words, following relatively open-ended conversations on indefinite futures (Dupuy's “occurring" time), people shifted to the

\footnotetext{
${ }^{12}$ Consider "Promethean shame" as one such effect of the future upon the present. According to Günther Anders, the shame of being born rather than made can arise with the fear of having been born too early [1]. Those who are fixated upon a future of technology that affords greater opportunities to make and remake themselves, will feel an effect upon their present in the form of anxiety: will I live long enough to live forever and to benefit from what the future holds?
}

catastrophe that was bound to come (Dupuy's "projected" time), discounting other scenarios as implausible in the face of likely technological failure.

\section{The Story of Stories}

If only to avoid spoilers, the remainder of this introduction will quickly sketch the learning process that transformed DEEPEN's original aspirations into suggestions for a kind of philosophical inquiry that might successfully move beyond the conversational mode of "responsible development" into a requalified political sphere. This learning process appears in three steps and is followed by a sample analysis at the intersection of social science and philosophy.

The story begins with "Narratives of mastery and resistance: Lay ethics of nanotechnology" by Sarah Davies and Phil Macnaghten. The authors uncover a set of five narratives which, they argue, inform the attitudes of lay publics to nanotechnology. There is no claim that these five stories of technological development are original or specific to nanotechnology. Instead, nanotechnology appears in these stories as an intensification of familiar trends, bringing to a head the latent conflict between the Enlightenment claim for mastery and control and historical experience of contingency and tragedy. If policy makers or promoters of nanotechnology wish to understand and take into account public concerns, they need to pay attention to the ways in which these narratives structure expectations.

The condensed version of Jean-Pierre Dupuy's "The Narratology of Lay Ethics" provides a philosophical analysis of the five narratives identified by Davies and Macnaghten. It would therefore appear that it follows DEEPEN's original aspiration to draw on lay attitudes and public concerns for the discovery of germane philosophical questions about nanotechnology. Dupuy's paper does not pursue this route straightforwardly, however. His analysis relates the five narratives to the problems of desire, evil, and the sacred in ancient mythology, and to the modern themes of alienation and exploitation. He thereby underscores the compelling quality and enduring character of the five narratives, showing, in a sense, their completeness and necessity. Dupuy also questions, however, whether the ancient and modern mythologies provide a cultural repertoire that can 
match the promise and peril of nanotechnologies and other emerging technologies. ${ }^{13}$

The final report of the DEEPEN project sought, in response to this assessment, to show that problems for philosophical reflection arise not directly from the five narratives but from Dupuy's critique of them as simultaneously necessary and inadequate. ${ }^{14}$ Arianna Ferrari and Alfred Nordmann here present a contextualized version of this report and propose tentative "Lessons for Nanoethics" that are informed by the critique of the conversational mode and its attendant consequentialism. These lessons underscore that one can leave the mode of conversation by requalifying the political sphere: though ethical issues cannot be settled by politics, an ethics of nanotechnology might serve to return nanotechnological research and development to the sphere of political deliberation and decision-making. ${ }^{15}$

Finally, Clare Shelley-Egan's "The ambivalence of promising technology" establishes promising as a problem of nanoethics and nanopolitics in the real world. It moves into the political sphere not only by reconstructing the current division of moral laborthat is, by showing how the social positioning of promoters of nanotechnology accommodates a conversationalist mode of ethics within a division of moral labor - but also, by extension, in suggesting the ways in which the language game of "responsible development and ethical concern" and its alternatives can be considered within a larger framework of an ethics of social positioning. One such alternative language game has been inaugurated by the European

\footnotetext{
${ }^{13}$ Dupuy's distinction between occurring and projected time remains in the background here. The transfer of the ancient myths regarding desire, evil, and the sacred into the conversational mode of contemporary publics must fail, he suggests implicitly, because contemporary publics behold the future without a sense of fate or destiny but as that which might or will occur. On the other hand, the fact that all five narratives end in catastrophe suggests the kind of inevitability which he considers a hallmark of projected time: it affords an opportunity to fixate upon this catastrophe.

${ }^{14}$ The report does not exhaust this heuristics. Rather than subtly drawing out the various dimensions of Dupuy's critique, it develops for its intended readership the general idea that, although we have many cultural resources to accommodate ourselves to nanotechnologies, these resources may well turn out to be insufficient for the task at hand.

${ }^{15}$ Alexei Grinbaum and his collaborators have pursued a different route forward from Dupuy's discussion of myth as a heuristic for nanoethical reflection [17].
}

Commission's proposed Code of Conduct for responsible research in nanoscience and nanotechnologies [7]. It is provocative precisely in that it calls for a renegotiating of the long-accepted division of moral labor and because it seeks to tie the assumption of responsibility to the creation of mutual commitments - for example in disclosure commitments by producers of nanomaterials. This "construction of co-responsibility" [20] leaves the conversational mode, defies consequentialism, empowers the political sphere, and views ethics as a conflict of principles that transcend individual action. However, a philosophical assessment of the EC's code of conduct cannot be delivered here. The DEEPEN project may have shown ways to move beyond the collation of concerns about nanotechnologies, but it has only begun to raise the questions that require sustained research and reflection in years to come.

\section{References}

1. Anders G (1956) Die Antiquiertheit des Menschen. Beck, München

2. Bensaude-Vincent B (2009) Comments on DEEPENReport, delivered at the public presentation of the report, Brussels, September 28, unpublished manuscript

3. Davies S, Kearnes M, Macnaghten P (2009) All things weird and scary: nanotechnology, theology and cultural resources. Culture and Religion 10(2):201-220

4. Davies S, Kearnes M, Macnaghten P (2010) Nanotechnology and public engagement: a new kind of (social) science? In: Kjolberg K, Wickson F (eds) Nano goes macro: social perspectives on nano sciences and technologies. Pan Stanford, Chicago

5. Dupuy J-P (1992) Two temporalities, two rationalities: a new look at Newcomb's paradox. In: Bourgine P, Wallise B (eds) Economics and cognitive science. Pergamon, New York, pp 191-220

6. Dupuy J-P, Grinbaum A (2004) Living with uncertainty: toward the ongoing normative assessment of nanotechnology. Techné 8(2):4-25

7. European Commission (2008) Commission recommendation of $07 / 02 / 2008$ on a code of conduct for responsible nanosciences and nanotechnologies research. European Commission, Brussels

8. Latour B (2004) Why has critique run out of steam? From matters of fact to matters of concern. Crit Inq 25-48

9. Latour B (2008) What is the style of matters of concern? Van Gorcum, Amsterdam

10. Lezaun J, Soneryd L (2007) Consulting citizens: technologies of elicitation and the mobility of publics. Public Underst Sci 16(3):279-297

11. Macnaghten P (2010) Researching technoscientific concerns in the making: narrative structures. Public Responses and 
Emerging Nanotechnologies, Environment \& Planning 41:23-37

12. Macnaghten P, Guivant J (forthcoming) Converging citizens? Nanotechnology and the political imaginary of public engagement in Brazil and the United Kingdom. Public Understanding of Science

13. Macnaghten P, Davies S, Kearnes M (2010) Narrative and public engagement: some findings from the DEEPEN project. In: von Schomberg R, Davies S (eds) Understanding public debate on nanotechnologies. Office for Official Publications of the European Communities, Luxembourg, pp 13-29

14. Nordmann A (2007) If and then: a critique of speculative nanoethics. Nanoethics 1(1):31-46

15. Nordmann A, Rip A (2009) Mind the gap revisited. Nat Nanotechnol 4:273-274

16. Nordmann A, Schwarz A (2010) Lure of the "Yes": the seductive power of technoscience. In: Kaiser M, Kurath M, Maasen S, Rehmann-Sutter C (eds) Governing future technologies: nanotechnology and the rise of an assessment regime. Springer, Dordrecht, pp 255-277
17. Pavlopoulos M, Grinbaum A, Bontems V (2010) Toolkit for Ethical Reflection and Communication on Nanotechnology. CEA, Saclay. Available at www.observatorynano. eu/project/catalogue/4ET/, accessed July 9, 2010.

18. Rip A, Shelley-Egan C (2010) Positions and responsibilities in the 'real' world of nanotechnology. In: von Schomberg R, Davies S (eds) Understanding public debate on nanotechnologies. Office for Official Publications of the European Communities, Luxembourg, pp 31-38

19. van Broekhuizen P, Schwarz A (2010) European trade union and environmental NGO positions in the debate on nanotechnologies. In: von Schomberg R, Davies S (eds) Understanding public debate on nanotechnologies. Office for Official Publications of the European Communities, Luxembourg, pp 81-108

20. von Schomberg R (2010) Organising collective responsibility: on precaution, codes of conduct and understanding public debate. In: Fiedeler U, Coenen C, Davies S, Ferrari A (eds) Understanding nano and emerging technologies: a volume from the s.net society. IOS, Amsterdam 